\title{
A ALFABETIZAÇÃO MUSICAL E OS PARADIGMAS EDUCACIONAIS
}

\begin{abstract}
Resumo
O artigo apresenta as concepções atuais de alfabetização musical e suas relações com as questões paradigmáticas da educação, expondo os diferentes tipos de paradigmas e suas modificações. A possibilidade de apresentar, relacionar e debater as questões referentes aos paradigmas e às contribuições de autores para a alfabetização musical, caracterizando o egresso, são outros objetivos deste trabalho. A relevância do tema está no escasso debate sobre os paradigmas na educação musical e na possibilidade que o seu estudo pode proporcionar ao educador no processo de alfabetização musical. De natureza bibliográfica e documental, o estudo se fundamenta nos trabalhos de Schafer (1992, 1997) e Swanwick (1979, 2003, 2014). Os resultados apontam para a nova tendência da alfabetização musical, que passa a ter um compromisso inclusivo, tornando-se acessível não só ao estudante que tem como objetivo ser um músico profissional, mas também a pessoas de diferentes contextos sociais.
\end{abstract}

Palavras-chave: Alfabetização musical; Paradigmas educacionais; Educação Musical

\footnotetext{
${ }^{1}$ Mestre em Educação, Pontifícia Universidade Católica do Paraná. Endereço: Rua Imaculada Conceição, 1155, Prado Velho, Curitiba, Paraná, Brasil 80215-901, Endereço eletrônico: alemaohn4@ hotmail.com.

${ }^{2}$ Mestre e doutora em Educação, Pontifícia Universidade Católica do Paraná. Endereço: Rua Imaculada Conceição, 1155, Prado Velho, Curitiba, Paraná, Brasil 80215-901, Endereço eletrônico: alboni.vieira@pucpr.br, alboni@alboni.com
} 


\section{INTRODUÇÃO}

Com a disseminação da educação musical em diferentes espaços de ensino como colégios, escolas de músicas, faculdades, projetos sociais e igrejas, foi aberta a possibilidade de reflexão sobre os diferentes tipos de práticas que estão sendo utilizadas atualmente, para a iniciação musical, em contextos tão heterogêneos.

Tradicionalmente, o início do estudo musical se dava com a utilização de métodos específicos, para o aprendizado de leitura das notações musicais, e livros com exercícios musicais organizados para a iniciação e desenvolvimento da parte técnica de como se tocar um instrumento musical. Pozzolli (1983) e Bona (1997) são obras consagradas para a iniciação da leitura e conhecimento da notação musical. Diferentes gerações de músicos iniciaram seus estudos utilizando esse tipo de literatura e, em alguns casos, só teriam a oportunidade de começar a praticar música num conjunto musical como uma banda ou coral depois de conseguir assimilar ao menos uma parte do conteúdo teórico proposto.

Esse processo de iniciação do estudante de música passou a dividir espaço com o aparecimento de novas metodologias de alfabetização musical, que não se detinham exclusivamente na leitura de notações ou na forma recomendável de se tocar um instrumento, mas apresentavam a oportunidade de expandir as possibilidades de envolvimento do indivíduo com a música (SWANWICK, 2014).

O surgimento dessas diferentes abordagens educacionais na música ocorreu por influência dos diferentes paradigmas da educação, que trouxeram novas ideias e possibilidades para serem experimentadas e exploradas. Para compreendermos essa mudança é necessário conhecermos os paradigmas educacionais, sua história, seu desenvolvimento e como podem ser associados à educação musical.

O conceito de paradigma surge no estudo elaborado por Kuhn em 1962, denominado As estruturas das revoluções científicas, conceituando que as mudanças científicas passam por um processo racional, possibilitando o surgimento de "chaves" do conhecimento. Essas chaves são debatidas, elaboradas e sistematizadas, sendo compartilhadas por toda a comunidade científica, e desse processo emergem os diferentes paradigmas.

Essa visão sobre a mudança paradigmática em um contexto amplo das ciências auxilia no entendimento de uma mudança paradigmática ocorrida em um contexto mais restrito, no caso, a educação. Este estudo impactou em outras áreas do conhecimento como a filosofia, sociologia, história e economia, proporcionando um intenso debate (KUHN, 1994). 
A educação musical foi influenciada pelos paradigmas educacionais, se apropriando de conceitos que fundamentaram as diferentes concepções de iniciação e formação de um estudante de música.

A relevância do tema proposto está no escasso debate sobre os paradigmas na educação musical e nas possibilidades que o seu estudo pode proporcionar ao educador no processo de alfabetização musical.

Devido aos benefícios que proporciona em sua prática, o ensino de música tem ganhado destaque e mostrado relevância na sua aplicação em diferentes contextos. O aprofundamento de metodologias de ensino-aprendizagem na alfabetização musical abre um leque de possibilidades que podem auxiliar educadores a elaborarem e propiciarem experiências pedagógicas musicais com um significativo grau de importância e comprometimento para todos os envolvidos.

Para uma melhor elaboração da relação entre a educação e as questões paradigmáticas, a questão norteadora desse estudo surge com a seguinte dúvida: Quais são os paradigmas da educação que influenciaram os processos de alfabetização na educação musical?

O principal objetivo deste trabalho foi identificar quais os paradigmas educacionais que influenciam os processos de alfabetização na educação musical. Outros objetivos foram relacionar os diferentes paradigmas com a educação musical e refletir sobre os desdobramentos da sua prática para o egresso estudante de música que participa dessas atividades.

Para possibilitar uma apresentação da música e sua relação com os contextos sociais de diferentes períodos, Fonterrada (2008) trouxe um profundo relato sobre o desenvolvimento histórico da música e da educação musical.

Kuhn (1994), Morin (2000) e Capra (1996) permitiram um aprofundamento em relação aos paradigmas, seus conceitos e desdobramentos, além de refletirem sobre a influência que eles exercem em nossa realidade, tendo na educação e, por consequência, na educação musical, uma das áreas do conhecimento que mais absorve esses impactos. Scruton (1982) serviu de base para o levantamento histórico das diferentes correntes de pensamento sobre o conhecimento humano, principalmente a partir do período conhecido como "Idade Moderna", sintetizando e sistematizando as tendências, servindo de auxílio para a compreensão das filosofias dos diferentes pensadores do período. Especificamente sobre a educação musical, a pesquisa trouxe dois grandes expoentes das novas abordagens, Swanwick (1979, 2003, 2014) e Schafer (1992,1997). Ambos são referências no âmbito das novas 
práticas, permitindo um processo de alfabetização musical com novas possibilidades e centrado nas experiências que podem propiciar aos estudantes.

A coleta de dados durante o processo investigativo ocorreu por meio de pesquisa bibliográfica e documental. A pesquisa bibliográfica tem como objetivo principal localizar, identificar e analisar os conceitos básicos e pertinentes ao assunto proposto, buscando em livros, artigos e pesquisas anteriores de diferentes autores o ponto inicial da pesquisa. Severino (2007) explica da seguinte forma o trabalho com pesquisa bibliográfica:

[...] tem por objetivo a descrição e a classificação dos livros e documentos similares, segundo critérios tais como autor, gênero literário, conteúdo temático, etc. dessa técnica resultam repertórios, boletins, catálogos bibliográficos. E é a eles que se deve recorrer quando se visa elaborar a bibliografia especial referente ao tema de trabalho. Fala-se de bibliografia especial porque a escolha das obras deve ser criteriosa, retendo apenas aquelas que interessem especificamente ao assunto (SEVERINO, 2007, p. 77).

A pesquisa documental teve relevância, por ser uma técnica fundamental no campo das pesquisas em ciências sociais e humanas. Segundo Severino (2007):

Tem-se como fonte documentos no sentido amplo[...]. Nesses casos, os conteúdos dos textos ainda não tiveram nenhum tratamento analítico, são ainda matéria-prima, a partir da qual o pesquisador vai desenvolver sua investigação e análise (SEVERINO, 2007, p. 122-123).

A análise de documentos é fundamental, pois grande parte das fontes escritas são a base do trabalho de investigação, sendo realizada a partir de documentos considerados autênticos cientificamente. O diálogo entre as abordagens metodológicas da pesquisa possibilita uma maior clareza e profundidade aos temas tratados.

Os resultados da pesquisa apontaram quais os paradigmas que exercem influência nas práticas de alfabetização musical, podendo ser trabalhados separadamente ou sendo relacionados, aumentando o repertório que um educador pode empregar na elaboração de atividades pedagógicas. Com o surgimento das novas concepções, a alfabetização na educação musical passa a ter um compromisso inclusivo, tornando-se acessível não só ao estudante que tem como objetivo ser um músico profissional, mas também a jovens, crianças, bebês, idosos e adultos de diferentes contextos sociais e econômicos, que podem ser beneficiados com a prática musical. 


\section{DESENVOLVIMENTO}

Através dos séculos, a música e a educação musical tiveram diferentes participações nas sociedades ocidentais. Na Grécia antiga, Platão e Aristóteles já refletiam sobre a relação entre a música, as emoções e a formação cívica no contexto da polis (FONTERRADA, 2008).

Na Idade Média, temos a influência dos escolásticos em toda a cultura educacional. A música também teve um espaço de destaque, se tornando um dos principais símbolos culturais desse período, que relacionavam elementos sacros com elementos pagãos, com uma forte influência cultural grega do período socrático de elaboração dos conhecimentos através da dialética (FONTERRADA, 2008). A partir do período conhecido como Renascimento, gradativamente emergiu um paradigma dominante, consequência da cultura da sociedade ocidental e das transformações que foram ocorrendo mais tarde, como a revolução científica, o iluminismo e a revolução industrial, Capra (1996) menciona que um dos primeiros responsáveis pelo avanço científico do pensamento humano foi Nicolau Copérnico (14731543) com sua tese sobre o heliocentrismo, que apresentou o fato de que era o planeta Terra que orbitava em torno do sol, e não o contrário, como se acreditava.

Uma grande influência na transição dos paradigmas científicos para a educação foi a de Francis Bacon (1561-1626). Apesar de não ser um teórico da educação, sua filosofia, baseada no empirismo, inspirou uma nova concepção de sistema científico e posteriormente educacional, com o livro Novum Organum (1962). Ele fez diversas críticas às técnicas de pesquisa aristotélicas utilizadas pelos escolásticos e apontou (de forma ainda especulativa e incompleta) outros caminhos para o avanço das ciências (SCRUTON, 1982). Nesse novo sistema científico foi proposto “seu método de 'indução' - a postulação de leis universais com base em instâncias observadas -, esperando desse modo promover o casamento legal e verdadeiro entre a faculdade empírica e racional" (SCRUTON, 1982, p. 30).

Com uma elaboração sistematizada de seu pensamento sobre o conhecimento, Bacon (1997) influenciou a educação a partir do momento em que incorporou a necessidade de ser sistematizada na sua teoria, para ser possível a transmissão de seu conteúdo. Sobre a influência de Bacon (1997) na educação, Batista (2010) relata que o Ocidente:

[...] lhe deve o mérito, ainda que indiretamente, de ser um dos principais autores de uma educação pautada na importância do conhecimento científico como instrumento imprescindível para a formação e a independência intelectual humana, razão pela qual o seu pensamento deve ser constantemente revisitado à guisa de serem 
exploradas as suas contribuições imediatas (que podem ser constatadas na filosofia) e remotas (as quais se aplicam à pedagogia) (BATISTA, 2010, p. 183).

O método educacional empirista é fundamentado na experiência e observação para construir suas bases, perceptíveis pelos sentidos humanos (SCRUTON, 1982).

A educação sofreu influência dos mesmos dogmas da teoria do conhecimento de Bacon (1997), na qual "o método indutivo parte sempre de fatos específicos, particularizados e observáveis, suficientemente catalogados e enumerados, para se chegar a uma conclusão geral, universal" (GALVÃO, 2007, 37). Esse paradigma continua a ganhar força com Galileu Galilei (1564-1642), desenvolvendo o reconhecimento quantificável da matéria, mas foi com René Descartes (1596-1650) que se teve de fato a inauguração da "Idade Moderna" e a culminação dessa linha de pensamento filosófico.

No ensaio de Descartes, $O$ discurso sobre o método (1637), foram estabelecidas novas abordagens de investigação científica, desenvolvendo um método analítico que se fundamenta na divisão dos objetos de estudo em ordem lógica, com o objetivo de trazer certezas sem a possibilidade de omissão. O impacto do pensamento de Descartes foi tão forte que mesmo as pesquisas de alguns cientistas contemporâneos tiveram mais projeção a partir do momento em que ganharam uma leitura cartesiana de suas concepções. "Só após o Cartesianismo é que a natureza do pensamento de Bacon veio a ser totalmente apreciada" (SCRUTON, 1982, p. 31). Descartes também antecipou muitos conceitos que foram elaborados por Isaac Newton (16421727), o qual, apoiado em seu sólido princípio matemático, propôs uma sistematização da natureza, sendo considerado um dos pontos principais da revolução que serviu de base para grande parte da produção científica posterior (SCRUTON, 1982).

Essas concepções de estudos matemáticos e científicos, que se tornaram conhecidos como "cartesianos", "mecanicistas" ou "newtonianos", proporcionaram grandes avanços nas ciências, mas acarretaram também a fragmentação dos conhecimentos. Tais abordagens científicas influenciaram o campo da educação, que foi forçado a responder e acompanhar as novas demandas impostas.

Um dos grandes exemplos do método empirista e de seu desdobramento na educação está em Locke (2013) e em sua tese da "tábula rasa", que repelia a hipótese do ser humano possuir algum conhecimento inato. Essa consideração logo se enraizou na educação, tornando o professor o símbolo e a autoridade mais importante no processo de ensino e aprendizagem. Com a influência de Bacon (1997), Descartes (2001) e Locke (2013), a educação ganhou 
pressupostos, como a necessidade de se desenvolver o conhecimento em diversas categorias para aprofundar seu estudo de modo específico, e a criação de sistemas gerais, que visavam abarcar todos esses conhecimentos estudados.

Na educação musical, temos o exemplo de Curwen (1886), que organizou seu método de piano baseado em conceitos como a necessidade de se partir dos exercícios mais fáceis para os mais difíceis, deixar de fora todas as exceções até que a regra geral fosse entendida, condicionar a mente com o treinamento do concreto antes do abstrato, ensinar o elementar antes do composto e apresentar um conteúdo de cada vez (CURWEN, 1886 apud SWANWICK, 2014).

Todas essas características são encontradas em nossa cultura educacional, estando presentes também no contexto da educação musical, principalmente no caso da música erudita, que trata de repertórios que podem remeter ao século XV.

Na educação musical, a alfabetização serve como ferramenta inicial no processo de aprendizado, desenvolvendo a capacidade de decodificação das notações musicais e o domínio técnico do instrumento ou da voz, tendo esses quesitos priorizados durante o desenvolvimento do estudante. Um exemplo prático ocorre no método de solfejo de Pozzoli (1983), que estimula não só a leitura, mas também a grafia. As atividades são organizadas de forma que, mesmo com alguma flagrante dificuldade, "o aluno deverá insistir neste exercício, porque da facilidade e rapidez em distinguir cada grupo rítmico derivará a sua firmeza e exatidão em grafar" (POZZOLI, 1983, p. 25).

Existem também livros diferentes para a iniciação e aperfeiçoamento para cada instrumento, especificamente. Citando alguns exemplos, para violão existe o método Carlevaro (1979), para piano o método Fletcher (1973) e para flautas o método desenvolvido por Moyse (1934). Os aspectos técnicos da execução são explicados e exemplificados com figuras do corpo humano ou analogias de sílabas como "tá" ou "dá" para a emissão das notas musicais. Cada instrumento apresenta inúmeros livros feitos para cada fase do processo de aprendizagem

Livros de métodos musicais específicos para instrumento de sopro ou cordas como Farkas (1962), Clarke (1934), Suzuki (1978) e Arban (1936), ainda são utilizados por alguns professores como única base na formação de um instrumentista, de forma literal. Cada detalhe, como posição das mãos no manuseio do instrumento e maneira correta de respirar, deve ser respeitado. Nesses casos, o processo de alfabetização musical e desenvolvimento técnico no instrumento ocorrem simultaneamente. Nos trabalhos de Beltrame (2008) e 
Baptista (2010), vemos a preocupação em adaptar estudos musicais de forma a não utilizar apenas um livro específico como meio de desenvolvimento musical. Mesmo assim, ainda se tem a necessidade de seguir de forma sistemática a metodologia proposta, como meio de alcançar os resultados musicais e artísticos desejados.

É perceptível a relação dessa abordagem de educação musical com o paradigma conservador. A alfabetização, durante o ensino e a aprendizagem, ocorre de forma sistemática, tendo o professor como figura responsável pela transmissão do conhecimento. Por sua vez, esse conhecimento é organizado de forma hierárquica, buscando privilegiar o desenvolvimento do estudante como intérprete musical capaz de atuar em nível profissional, priorizando suas habilidades técnicas e interpretativas, potencializando a sua performance musical.

Influenciada pela participação de psicólogos e educadores contrários às formas educacionais vigentes na época, se inicia um processo diferente de alfabetização, conhecido por Escola Nova. Os principais ícones dessa abordagem foram John Dewey (1859-1952), Maria Montessori (1870-1952) e Jean-Ovide Decroly (1871-1932). Essa abordagem terá o aluno como figura central, respeitando sua personalidade e seu ritmo de desenvolvimento. $\mathrm{O}$ professor, na Escola Nova, tem a função de facilitador da aprendizagem, e, na avaliação, evita a padronização de resultados. O processo de ensino é baseado em métodos, unidades de experiência e trabalhos em grupo, levando em conta as exigências psicológicas pertinentes a cada faixa etária (BEHRENS, 2013).

Na música, um dos mais conhecidos educadores que utilizavam essa abordagem é Dalcroze (1925). Percebendo as mudanças que ocorriam na arte e na educação, Dalcroze desenvolve um método de ensino musical fundamentado no movimento e na escuta ativa da música. A alfabetização, nesse caso, acontece em meio a atividades de movimento e interação física do estudante, objetivando maior participação nas atividades (MATEIRO; ILARI, 2011). A grande contribuição de Jaques-Dalcroze está no fato de ter retirado o aluno da educação "livresca" a que estava submetido e fazê-lo participar de uma série de exercícios que demandam atuação física, tendo o corpo como objeto de expressão de uma representação dos elementos musicais. Através dos movimentos corporais, o aluno passa a experimentar sensações físicas em relação à música, abrindo caminhos para a criatividade e a expressão. $\mathrm{O}$ grande objetivo de Jaques-Dalcroze era fazer o aluno experimentar e sentir, para somente depois dizer “eu sei” (MATEIRO; ILARI, 2011). 
Apesar de já ter uma visão diferenciada de alfabetização musical, por ter na reprodução do conhecimento seu principal objetivo, a abordagem escolanovista também é considerada uma pedagogia conservadora de educação, por se desenvolver através de métodos estabelecidos e considerar a ideia de que uma criança se desenvolve através de estágios cumulativos que podem ser empiricamente observados, analisados e avaliados.

Como consequência, com uma visão unicamente tecnicista na educação musical, o estudante pode estar fadado a ser apenas um repetidor sonoro, eliminando o fator emocional da música. Nesse sentido podemos corroborar com a consideração de Morin (2000) sobre a redução do papel da criatividade e emotividade, argumentando que:

Pode também cegar e conduzir a excluir tudo aquilo que não seja qualificável e mensurável, eliminando, dessa forma, o elemento humano do humano, isto é, paixões, emoções, dores, e alegrias. Da mesma forma, quando obedece estritamente ao postulado determinista, o princípio de redução oculta o imprevisto, o novo e a invenção (MORIN, 2000, p. 42).

Com o desenvolvimento da ciência e o surgimento de novas teorias, como a física quântica e a incapacidade de responder as novas demandas sociais, o paradigma newtonianocartesiano entra em crise.

Dessa forma, temos o surgimento de um novo paradigma. Morin (2000) vai versar sobre a percepção que um conhecimento fragmentado não atende mais as necessidades existentes dizendo que um contexto tem características que não são encontradas em suas subdivisões, e essas subdivisões separadas podem descaracterizar-se ou limitar-se. É preciso analisar o contexto geral para conhecer as partes (MORIN, 2000). O novo paradigma transcende o antecessor, relacionando o universo em uma imensa teia de informações, comportamentos e ideias, todas se conectando com as mais diferentes áreas do conhecimento e da sociedade. Interligar todas as visões do mundo moderno passa a ser uma necessidade primária, possibilitando não só o descobrimento de novas ciências, mas as possibilidades de transformação pessoal (FERGUSON, 1992).

Rompendo com a concepção de ciência anterior e absorvendo as características da sociedade sempre em transformação, o novo paradigma surge amalgamando diversos contextos, sendo conhecido atualmente como paradigma da complexidade. Esse nome origina-se justamente pela necessidade do novo paradigma em atender a toda rede de diferentes informações complexas que temos nos dias atuais (CAPRA, 1997). Essas abordagens dialogam diretamente com o pensamento da educação musical moderna, 
principalmente a partir da segunda metade do século $\mathrm{XX}$, possuindo uma visão integrada, inserindo o indivíduo em uma sociedade plural, podendo proporcionar a superação da visão fragmentada dos conhecimentos, relacionando o trabalho com o intelecto (BEHRENS, 2013).

Como exemplo dessa abordagem na educação musical, temos Swanwick (1979), propondo uma forma de alfabetização que não segue uma regra ou sequência pré-estabelecida de atividades, mas utiliza parâmetros que estimulam o estudante a se desenvolver musical e cognitivamente. Esse modelo ficou conhecido como $\mathrm{C}(\mathrm{L}) \mathrm{A}(\mathrm{S}) \mathrm{P}$, e busca uma participação ativa e direta com a música, fazendo com que o estudante deixe de ter um papel passivo no processo ensino-aprendizagem (SWANWICK, 1979).

C(L)A(S)P é a abreviatura desses parâmetros, que em português traduziu-se como (T)EC(L)A. Essas atividades são baseadas em exercícios de execução, composição e apreciação musical como elementos fundamentais, sendo auxiliadas por exercícios técnicos e a utilização de literatura relacionada à música, como atividades de apoio. Os parâmetros são organizados objetivando que o estudante tenha uma vivência musical perpassando todas essas atividades, organizadas de maneira a privilegiar um dos parâmetros ou mesclá-los de acordo com a proposta de determinada atividade elaborada pelo professor (WEILAND, 2006).

A sigla original em inglês é composta pela letra C, que representa a 'composição'; A representa 'apreciação'; e P representa 'performance' (que em português se traduziu como execução ou desempenho). As atividades de complementação que ficam entre parênteses (ocorrendo de forma similar na tradução em português) auxiliam nas atividades anteriores. A letra S representa skill acquisition (que em português foi traduzido como técnica, ou aquisição de habilidades); e a letra L representando literature studies (em português traduzido como literatura) (FRANÇA; SWANWICK, 2002).

Essas atividades transformam-se em um tipo de pesquisa que além de contribuir para a alfabetização também estimula a criatividade dos participantes. O objetivo é que os diferentes parâmetros se relacionem e auxiliem o desenvolvimento mútuo um dos outros, possibilitando uma experiência musical mais completa e prática. Os parâmetros podem ser trabalhados separadamente, mas é na relação entre eles que é aprofundada a experiência musical dos estudantes, sempre levados a um lugar ativo na participação musical. Com essas possibilidades de atividades será possível uma maior clareza para o professor e para os estudantes sobre o significado musical para cada indivíduo durante o processo, independentemente da idade. Dessa forma, é possível considerar que todos estarão envolvidos afetiva e psicologicamente o processo de aprendizagem musical. 
Outra referência para a educação musical é Schafer (1992, 1997), com sua ideia de que o processo de alfabetização deveria concentrar-se nos sons, pois é daí que se origina a música. O autor critica o uso exclusivo da notação musical tradicional, pois "a notação musical convencional é um código extremamente complicado, e para dominá-lo são necessários anos de treinamento" (SCHAFER, 1992, p. 295). Uma das atividades mais conhecidas elaboradas por Schafer é a "Paisagem Sonora", que descreve o ambiente sonoro de forma cuidadosa e crítica, propondo atividades de percepção dos diferentes ruídos do mundo moderno, objetivando o desenvolvimento de uma maior sensibilidade do sentido de audição (SCHAFER, 1997).

A partir dessa atividade, qualquer exercício teórico ganha novas dimensões, convidando o estudante não só a repetir, mas a analisar e associar determinado exercício, por exemplo de leitura, à sua realidade. Schafer relata que:

Descobri que não é necessário que os exercícios de audição se limitem a fazer juízos distintos a respeito dos sons que encontramos contidos no espaço e tempo de composições e salas de concerto. Um solfejo pode ser trabalhado a partir de quaisquer sons disponíveis no meio ambiente. O principal é que esses sons não devem ser apenas ouvidos, mas também analisados e julgados. Se, por exemplo, estivermos ouvindo o murmurar de folhas ao vento e passar uma escavadeira, o professor não deve perder a oportunidade de apontá-la como um exemplo de má orquestração (SCHAFER, 1992, p. 287).

Qualquer elemento sonoro encontrado no ambiente se torna uma ferramenta significativa no processo de ensino e aprendizagem na alfabetização, exigindo reflexão, criticidade e sensibilidade do professor e dos alunos na prática das atividades propostas.

Swanwick (2003) salienta diversas vezes o conceito de "educação holística" na música, valorizando as relações entre diferentes áreas do conhecimento como a psicologia, a sociologia e as práticas pedagógicas, agregando o valor artístico e o significado da música para pessoas em contextos sociais distintos.

Existe a necessidade de se estabelecer uma analogia entre a educação e a prática musical, defendendo a criatividade e a iniciativa de desenvolvimento coletivo, sem deixar de valorizar o trabalho individual e o estímulo da criatividade dos estudantes. Para Schafer:

A aula de música é sempre uma sociedade em microcosmo, e cada tipo de organização social deve equilibrar as outras. Nelas deve haver um lugar, no currículo, para a expressão individual; porém, currículos organizados previamente não concedem oportunidade para isso [...] (SCHAFER, 1992, p.267). 
A educação musical, no final do século XX, se caracterizou por defender e elaborar metodologias que tornam possíveis a vivência musical para qualquer pessoa, em qualquer faixa etária.

Segundo Kater, "entre as funções da educação musical teríamos a de favorecer modalidades de compreensão e consciência de dimensões superiores de si e do mundo, de aspectos muitas vezes pouco acessíveis no cotidiano, estimulando uma visão mais autêntica e criativa da realidade" (KATER, 2004, p.44).

A educação musical deixou de ter uma metodologia estritamente técnica e embasada em fundamentos conservadores e passou a ser também uma atividade de desenvolvimento cognitivo, aplicável para qualquer pessoa. Esses métodos são conhecidos como "métodos ativos". Para Figueiredo, métodos ativos são:

\begin{abstract}
A experiência direta com a música a partir da vivência de diversos elementos musicais é o que caracteriza os métodos ativos de educação musical. Nesta perspectiva, o aluno participa ativamente dos processos musicais desenvolvidos em sala de aula, processos estes que oportunizam o contato com várias dimensões do fazer musical. Com essas abordagens, evita-se o foco na teoria musical e nos exercícios descontextualizados, que muitas vezes, desestimulam a aprendizagem musical exatamente porque não são reconhecidos como experiências musicais válidas (FIGUEIREDO, 2012, p. 85).
\end{abstract}

Com essas novas concepções de alfabetização musical, tivemos o impacto da música como forma de contribuição na educação e meio de desenvolvimento do indivíduo, proporcionando seu crescimento social e cultural, tendo como uma de suas metas, a diminuição da desigualdade social, por meio de ações informais de educação.

É possível sugerir que os fundamentos das diferentes abordagens inovadoras influenciaram a educação musical no século XX e estão presentes atualmente no século XXI. Sobre esse momento de transposição do antigo paradigma e valorização do ser humano, suas experiências e suas potencialidades. Capra (1996) disserta que "a educação transpessoal é mais humana do que a educação tradicional e mais rigorosa, sob o aspecto intelectual, do que muitas alternativas anteriores" (CAPRA, 1996, p. 272).

Devido aos benefícios que proporciona em sua prática, o ensino de música tem ganhado destaque e mostrado sua relevância em sua aplicação em diferentes contextos de aprendizagem. No trabalho organizado pelas autoras Mateiro e Ilari (2011), algumas dessas novas práticas na educação musical foram abordadas e analisadas para possibilitar sua utilização em diferentes espaços de educação musical. Para isso, uma questão levantada foi a necessidade de um professor reflexivo, que estimule seus estudantes da mesma forma, 
levando em conta questões como estar consciente do contexto social, histórico e cultural em que cada autor elaborou seu método, entender o papel atribuído ao professor e ao aluno nas diferentes atividades.

Para um professor ter a oportunidade de refletir suas concepções de educação e colocá-las em prática existe a necessidade de "avaliar o próprio processo de ensino e aprendizagem em curso, tomando decisões que permitam realizar os objetivos propostos, dentro de limites e possibilidades da situação educativa concreta" (PENNA, 2011, p. 16). Nesse ponto, a teoria e a prática educacional se interpenetram, aumentando as possibilidades educativas do professor de música. Cada paradigma educacional oferece importantes conceitos e privilegiam determinados pontos para a construção de um ambiente educativo prolífico. Valorizando a importância de um professor reflexivo, um dos pontos fundamentais para os novos paradigmas da educação musical é oferecer uma experiência significativa para todos os envolvidos no processo de ensino e aprendizagem (SWANWICK, 1979). Alinhado com essas considerações, Swanwick (1979) também considera a necessidade do professor de música desenvolver conhecimentos teóricos e artísticos que possam enriquecer suas possibilidades pedagógicas. O estudo dos paradigmas educacionais e sua relação com as diferentes metodologias de alfabetização musical permite buscar "respostas pedagógicas para a necessidade do cotidiano" (PENNA, 2011, p. 19).

Essas "respostas pedagógicas", contudo, podem ser elaboradas pelos docentes levando em conta as contribuições oferecidas pelos paradigmas tradicionais, por meio de reapropriações, e se aprofundando nas novas concepções dos paradigmas inovadores. Monroe (1983) aponta que o estudo de diferentes tendências educacionais e seus contextos históricos, sociais e culturais permite que suas contribuições sejam abordadas como meios de se expandir os conhecimentos e possibilidades de suas aplicações. Um conhecimento superficial ou insuficiente de diferentes metodologias de ensino pode se apresentar como simples dogmas, sem um conteúdo efetivamente significativo, capaz de acrescentar contribuições no processo de desenvolvimento educacional dos estudantes.

Com a reflexão sobre as questões paradigmáticas na educação é possível transcender um simples debate sobre metodologias de ensino para se buscar elementos mais profundos que permeiam essas práticas educativas. Ligando esse tema à educação musical, Penna (2011) considera que "a questão não se resume, contudo, a escolher um método e utilizá-lo de forma flexível, procurando adaptá-lo à faixa etária de nossos alunos ou atualizando seu repertório, por exemplo, pois tais propostas pedagógicas carregam uma concepção de mundo..." 
(PENNA, 2011, p. 20). Dessa forma, com o aprofundamento teórico e prático em relação aos paradigmas inovadores e a possibilidade de releituras e reapropriações de diferentes metodologias consideradas conservadoras, a educação musical pode potencializar seu alcance e oferecer todos os benefícios de sua prática para estudantes de diferentes contextos educativos.

A partir do século XX, principalmente da segunda metade, os principais educadores musicais deixaram de se preocupar exclusivamente com a formação de estudantes de música com o compromisso unicamente profissionalizante, para contemplar uma maior abertura para os objetivos da educação musical. A educação musical passa a ser uma atividade acessível a todos os indivíduos, bebês, crianças, adolescentes, jovens e adultos, e nesse sentido, passa a ter um caráter inclusivo, oferecendo seus benefícios a todos que se veem motivados a praticar algum tipo de atividade musical (MATEIRO; ILARI, 2011). No Brasil, importantes pesquisadores representantes dessas novas concepções de educação musical são Fonterrada (2008), Carlos Kater (2004), Maria Laura Penna (2001), Jussamara Souza (2009), Luciana Del Ben (2001) e Liane Hentschke (1996). Esses professores têm em comum a busca de transformar o estudante de música em um elemento ativo, dentro do processo de ensino e aprendizagem, fator fundamental encontrado no paradigma inovador.

Como desdobramentos dessas novas abordagens, começaram a surgir exemplos de mudanças pedagógicas em algumas instituições de ensino. Um importante exemplo está na Escola de Música e Belas Artes do Paraná. Keith Swanwick se tornou o principal autor utilizado nas atividades educacionais nos cursos de extensão da instituição.

A iniciativa de mudança pedagógica resultou na elaboração do Referencial Acadêmico e Administrativo do Programa de Extensão em Música da Escola de Música e Belas Artes do Paraná (EMBAP, 2000). Foi na elaboração e aplicação do conteúdo desse documento no programa de extensão da EMBAP que se deu o início da aplicação do modelo educacional de Keith Swanwick nessa instituição, até sua chegada nas matérias de Didática no curso de Licenciatura em Música.

\section{CONSIDERAÇÕES FINAIS}

Neste artigo, relatamos de forma sintética a importância que a música teve e tem em diferentes contextos sociais. Pudemos identificar quais os paradigmas que influenciaram na prática educacional musical e seus desdobramentos. 
A partir dessas transformações na prática educacional, os paradigmas passaram a ser exercidos também na educação musical, buscando um processo de alfabetização musical que objetivava a formação de um músico virtuose, capaz de dominar todo o repertório composto para seu instrumento musical, voltado prioritariamente para potencializar o desempenho do seu praticante

Os novos paradigmas buscam uma ação mais dinâmica e inclusiva, possibilitando que estudantes oriundos de diferentes contextos sociais e com diferentes faixas etárias possam assimilar os conteúdos e associá-los, conforme sua vivência musical adquirida, antes do ingresso nos estudos musicais para, a partir desse ponto, trabalhar com novos conceitos e sonoridades da linguagem musical.

Os envolvidos no processo de ensino e aprendizagem devem ter consciência das concepções educacionais musicais teóricas e práticas que se propõem a trabalhar. O estudante deve ter um papel de pensador ativo e crítico em seu contexto educativo, aprimorando seu desempenho, a assimilação e a produção do conhecimento em relação ao modelo de ensino proposto.

É necessário que o professor saiba administrar essas funções sem perder o objetivo da educação musical, que é de transcender o universo musical imediato do aluno, apresentando-o diante de manifestações musicais de diversas épocas e sociedades. Para isso, também pode se fazer necessária a utilização de abordagens educacionais consideradas conservadoras, pois elas permitem o desenvolvimento de habilidades que são inerentes à prática musical, porém, sua aplicação exclusiva pode tornar-se prejudicial para o estudante.

Como resultados dessas novas concepções de alfabetização musical, temos consciência do comportamento num contexto de trabalho coletivo, do desenvolvimento de uma "identidade" em relação à comunidade e de diferentes percepções do mundo, de como o estudante está inserido nessa realidade, contribuindo para aprimorar seu raciocínio e desenvolvimento intelectual, e não apenas desenvolvendo uma habilidade técnica numa execução musical.

A educação musical se torna uma ferramenta importante dentro das práticas informais de ensino, devido à capacidade de desenvolver conceitos como socialização, respeito mútuo, adaptação de cada pessoa ao grupo e a diferentes culturas, construção da identidade coletiva e aplicação de regras de condutas éticas para o bom funcionamento do trabalho. Essas características são fundamentais tanto no trabalho de educação musical como em todas as práticas de ensino, tendo como principal objetivo o desenvolvimento da pessoa. Esse talvez 
seja o grande motivo da importância da música num contexto educacional, sendo uma forma de desenvolver intelectualmente aqueles que participam desta atividade.

A alfabetização na educação musical passa a ter um compromisso inclusivo, tornandose acessível não só ao estudante que tem como objetivo ser um músico profissional, mas também a jovens, crianças, bebês, idosos e adultos de diferentes contextos sociais e econômicos, que poderão usufruir dos benefícios que a prática musical proporciona.

As reflexões durante o processo investigativo permitiram perceber que essas novas abordagens devem incentivar os professores a buscar inserir uma concepção de educação musical centrada numa visão holística, na qual o aluno busca a produção do conhecimento. A partir da utilização dessas práticas, podemos considerar que todos os envolvidos no processo de ensino e aprendizagem estão inseridos em uma concepção educacional mais próxima de uma abordagem significativa também na educação musical.

\title{
MUSICAL LITERACY AND EDUCATIONAL PARADIGMS
}

\begin{abstract}
The article presents us contemporary conceptions of musical literacy and its relation to educational paradigmatic issues, thus exposing different types of paradigms and their modifications. The possibility to relate and discuss issues related to these paradigms and to the contributions from different authors to musical literacy issues, characterizing graduates, are also among the objectives of this work. The relevance of these issues is in the few existing debates on the paradigms within music education as well as within the possibility of such a study being able to provide useful material for educators. Of bibliographical and documentary nature, this study is based on the works of Schafer $(1992,1997)$ and Swanwick $(1979,2003$, 2014). The results point to the new trend of musical literacy, with an inclusive commitment, made accessible not only to the student who aims to be a professional musician, but also to people from different social contexts.
\end{abstract}

Keywords: Musical Literacy; Educational Paradigms; Music Education

LA ALFABETIZACIÓN MUSICAL Y LOS PARADIGMAS EDUCACIONALES

\section{Resume}


El artículo presenta las concepciones actuales de la alfabetización musical y su relación con los temas paradigmáticos de la educación, la exposición de los diferentes tipos de paradigmas y sus modificaciones. La posibilidad de que, relacionarse y discutir temas relacionados con los paradigmas y los autores de las contribuciones a la alfabetización musical, que caracterizan a la salida son otros objetivos de este trabajo. La relevancia del tema es escasa en el debate sobre los paradigmas en la educación musical y la posibilidad de que su estudio puede proporcionar al educador en proceso de alfabetización musical. Naturaleza bibliográfica y documental, el estudio se basa en el trabajo de Schafer $(1992,1997)$ y Swanwick (1979, 2003, 2014). Los resultados apuntan a la nueva tendencia de la alfabetización musical, que se sustituye por un compromiso incluyente se pone a disposición no sólo para el estudiante que aspira a ser un músico profesional, pero también personas de diferentes contextos sociales.

Palabras clave: Música de Alfabetización; Paradigmas Educativos; La Educación Musical

\section{REFERÊNCIAS}

ARBAN, Jean-Baptiste. Complete conservatory method for trumpet or cornet. New York: Carl Fischer, 1936.

BACON, Francis. Novum organum. Tradução: José Reis de Andrade. São Paulo: Nova Cultura, 1997.

BATISTA, Gustavo Araújo. Francis Bacon; para uma educação científica. Revista Teias. Rio de Janeiro, n. 23, p. 163-184, set./dez. 2010.

BAPTISTA, Paulo Cesar. Metodologia de estudo para trompete. 2010. 67 f. Dissertação (Mestrado em Musicologia) - Universidade de São Paulo, 2010.

BELTRAMI, Clóvis Antônio. Estudos dirigidos para grupos de trompetes: fundamentos técnicos e interpretativos. 2008. 189f. Dissertação (Mestrado em Música) - Universidade Estadual de Campinas, 2008.

BEHRENS, Marilda Aparecida. O paradigma emergente e a prática pedagógica. 6. ed. Petrópolis: Editora Vozes, 2013.

BONA, Paschoal. Método musical: São Paulo: IGAL, 1997.

CAPRA, Fritjof. A teia da vida. Uma nova compreensão científica dos sistemas vivos. São Paulo: Cultura, 1996. 
O ponto de mutação. São Paulo: Cultrix, 1997.

CARLEVARO, Abel. Escuela de la guitarra: exposición de la teoría instrumental. Buenos Aires: Barry, 1979

CLARKE, Herbert Lincoln. Technical studies. New York: Carl Fischer, 1934.

DEL BEN, Luciana Marta. Concepções e ações de educação musical escolar: três estudos de caso. 2001. 339f. Tese (Doutorado em Música) - Universidade Federal do Rio Grande do Sul, Porto Alegre, 2001.

DESCARTES, René. Discurso do método. Tradução de Galvão, M. E. São Paulo: Martim Fontes, 2001.

EMBAP. Referencial acadêmico e administrativo. Curitiba, 2000.

FARKAS, Philip. The art of brass playing. Rochester: Wind Music, 1962.

FERGUSON, Marylin. A conspiração aquariana. Tradução de Costa, C. E. Rio de Janeiro: Record, 1992.

FLETCHER, Leila. The Leila Fletcher piano course. New York: Montgomery Music, 1973.

FIGUEIREDO, Sérgio Luiz Ferreira. A educação musical do século XX: os métodos tradicionais. In: ALUCCI, Renata; JORDÃO, Gisele; MOLINA, Sergio; TERAHATA, Adriana Miritello. A música na escola. São Paulo: Alucci e Associados Comunicações, 2012. Cap. 2, p. 85-87. Disponível em:

<http://www.amusicanaescola.com.br/pdf/Sergio_Luiz_Figueiredo.pdf > Acesso em: 17 mai. 2014.

FONTERRADA, Marisa Trench de Oliveira. De tramas e fios. Um ensaio sobre música e educação. São Paulo: Editora Unesp, 2008.

FRANÇA, C.; SWANWICK, K. Composição, apreciação e performance na educação musical: teoria, pesquisa e prática. Revista Em Pauta, v. 13, n. 21, p. 6-41, 2002.

GALVÃO, Roberto Carlos Simões. Francis Bacon: teoria, método e contribuições para a educação. Revista Interthesis. Florianópolis, n. 2, p. 32-41, jul./dez. 2007.

HENTSCHKE, Liane. Analogia entre o desenvolvimento musical e o desenvolvimento do jogo: uma análise crítica. Revista Em Pauta, Porto Alegre, n. 12/13, p. 17-34, 1996.

JAQUES-DALCROZE, Émile. Ritmo, música e educazione. Milão: Ulrico Hoepli Ed., 1925.

KATER, Carlos. O que podemos esperar da educação musical em projetos sociais. Revista da Abem, Porto Alegre, n.10, p.43-51, mar. 2004.

KUHN, Thomas Samuel. A estrutura das revoluções científicas. São Paulo: Perspectiva, 1994. 
MONROE, Paul. História da educação. São Paulo: Nacional, 1983.

MATEIRO, Teresa; ILARI, Beatriz. Pedagogias em educação musical. Curitiba, 2011.

MORIN, Edgar. Os sete saberes necessários à educação do futuro. São Paulo: Cortez, 2000.

MOYSE, Marcel. De la sonorité - art et technique. Paris: Alphonse Leduc, 1934.

PENNA, Maura. (Coord.). É este o ensino de artes que queremos? Uma análise das propostas dos parâmetros curriculares nacionais. João Pessoa: Editora Universitária/CCHLA/PPGE, 2001.

Apresentação. In: MATEIRO, Teresa; ILARI, Beatriz. Pedagogias em educação musical. Curitiba, 2011.

POZZOLI, Ettore. Guia teórico-prático para o ensino do ditado musical. São Paulo: Ricordi, 1983.

SCHAFER, Raymond Murray. A afinação do mundo. Tradução: Marisa Trench Fonterrada. São Paulo: Unesp, 1997.

. O ouvido pensante. Tradução: Marisa Trench Fonterrada. São Paulo: Unesp, 1992.

SCRUTON, Roger. Introdução à filosofia moderna: de Descartes a Wittgenstein. Tradução: Alberto Oliva e Luis Alberto Cerqueira. Rio de Janeiro: Zahar, 1982.

SEVERINO, Antônio Joaquim. Metodologia do trabalho científico. São Paulo: Cortez, 2007.

SOUZA, Jussamara et al. Aprender e ensinar música no cotidiano. 2. ed. Porto Alegre:

Sulina, 2009.

SUZUKI, Shinichi. Suzuki violin school: violin part v. I. Miami: Warner Bros Publications, 1978.

SWANWICK, Keith. A basis for music education. London: NFER, 1979.

. Ensinando música musicalmente. Rio de Janeiro: Moderna, 2003.

. Música, mente e educação. Tradução: Marcell Silva Steuernagel. Belo Horizonte:

Autêntica, 2014.

WEILAND, Renate Lizana. Aspectos figurativos e operativos da aprendizagem musical de crianças e pré-adolescentes, por meio do ensino de flauta doce. 156f. Dissertação (Mestrado em Educação) - Universidade Federal do Paraná, 2006.

Data de recebimento: 24/05/2015

Data de aceite: $15 / 02 / 2016$ 